\title{
Shear Strength of Flat Joint considering Influencing Area of Bolts
}

\author{
Hang Lin $(\mathbb{D}$, Penghui Sun, and Yifan Chen $\mathbb{D}$ \\ School of Resources and Safety Engineering, Central South University, Changsha, Hunan 410083, China \\ Correspondence should be addressed to Yifan Chen; 1051361824@qq.com
}

Received 14 July 2020; Revised 23 October 2020; Accepted 28 October 2020; Published 16 November 2020

Academic Editor: Giosuè Boscato

Copyright (c) 2020 Hang Lin et al. This is an open access article distributed under the Creative Commons Attribution License, which permits unrestricted use, distribution, and reproduction in any medium, provided the original work is properly cited.

\begin{abstract}
Bolt is popular in the reinforcement of geotechnical engineering, which can significantly improve the strength and stability of jointed rock mass. For bolted joint, the bolting area is a certain scope instead of the entire joint surface; therefore, it is necessary to study the effect of bolt influencing area on the shear strength of rock joints. In this paper, a series of laboratory direct shear tests were executed on the bolted joints to explore the influence of bolts on the joint shear strength, as well as the influencing area of bolt. Via successively changing bolting angle and bolt number, the shear stress-shear displacement curves of bolted joints were recorded and the variation law of shear strength was analyzed. Based on the assumption of the circular influencing area of bolt, the influence coefficient $m$ (defined as the diameter ratio of the influencing area to the bolt) was introduced to establish the theoretical calculation model of the shear strength of bolted joint, which was verified by test results. Furthermore, the value of $m$ was changed, and the shear strengths of bolted joints under different bolting condition were calculated to compare with the test results. The average relative error $E_{\text {ave }}$ was selected to determine the optimal value of $m$ under the corresponding bolting condition, and it tends to sufficiently small values under the case of $m>30$ for one-bolted joint and $m>25$ for two-bolted joint, as well as $m>20$ for three-bolted joint, which demonstrates that $m$ can be applied to effectively calculate the actual influencing area of bolt.
\end{abstract}

\section{Introduction}

Joints widely exist in the natural rock mass, and the majority of failures in geotechnical engineering are caused by joint instability [1-9]. Bolting technology is the predominant means in geotechnical engineering reinforcement, which is adopted in mines, tunnels, slope, and dam foundation and other major projects. To date, scholars and experts have executed multitudinous theoretical and experimental studies on the bolted rock mass [10-15], which undoubtedly deepen the understanding of the bolting mechanism of jointed rock mass and provide certain foundation and conditions for further researches. However, those researches mainly focus on the tests without considering the group bolting effect, while bolts are usually systematically used in practical engineering. The arrangement of bolts significantly affects the bolting efficiency and engineering input, in which case it is inevitable to study the influencing area of the bolt to reach the optimal bolting efficacy. With respect to this point, there exist various opinions. For example, Chen et al. [16] believed that the influencing area of the bolt was the entire joint surface and established the calculating formula of the shear strength of bolted joint considering dilatancy characteristics. Liu et al. [17] considered the influencing area of bolt rectangular, which can be obtained by the product of bolt diameter and joint width or bolting interval. According to Teng et al. [18], however, it is less possible for the bolt to produce a rectangular influencing area in the actual shearing process, while the crack around the bolt will continuously extend in all directions until failure occurs under the interaction of shear force and axial force, ultimately forming a circular or elliptical section. In addition, the group bolting effect should also be taken into consideration when the number of bolts increases.

Based on the above considerations, the direct shear test on bolted joints was implemented, the number and inclination of the bolt were changed, respectively, and the test results were analyzed. Besides, a theoretical calculation model of bolted joint shear strength considering the influencing area was proposed, which was verified by the comparison between the calculated value and test results. 


\section{Laboratory Tests}

2.1. Sample Preparation. A similar material was selected to simulate the jointed rock, the direct shear test was performed, and the shear stress-shear displacement curve was recorded under constant normal load [19-21]. The specific model contains two parts, and the joint was simulated by the interface of two rock blocks, forming a joint rock with the size of $150 \times 150 \times 120 \mathrm{~mm}$ (see Figure 1). The bolt was represented by using the same material in Lin et al. [19] work. The installation angle of the bolt was set at $45^{\circ}$ and $90^{\circ}$, respectively, and the number of bolts ranged from 1 to 3 . The bolts were arranged as follows:

(1) When one bolt was used, the bolt was placed at the joint center.

(2) When two bolts were used, the bolts were arranged on the central axis perpendicular to the shearing direction, dividing the central axis into 3 parts on average at the interval of $50 \mathrm{~mm}$.

(3) When three bolts were used, the bolts were arranged on the central axis perpendicular to the shearing direction, dividing the central axis into 3 parts on average at the interval of $37.5 \mathrm{~mm}$.

During the process of producing jointed rock, the lower parts were poured first, and the bolts were inserted into the sample according to the predetermined inclination angle and number. 24 hours later, the mold was removed, and the upper parts were poured, as shown in Figure 1. Then, the sample was placed in an incubator for 28 days. To minimize the influence of the concrete strength difference of each sample on the test results, all the simulated rock blocks in this test were poured with the same proportion and the same batch of cement mortar.

RYL-600 microcomputer-controlled rock shear testing machine was adopted to conduct direct shear tests [22-25]. The normal load was set: $10,20,30,40$, and $50 \mathrm{kN}$, respectively, corresponding to normal tress of $0.45,0.89,1.33$, 1.78 , and $2.22 \mathrm{MPa}$. The loading speed was $1 \mathrm{~mm} / \mathrm{min}$. In order to obtain the basic parameters of the material under this ratio, three standard cylindrical samples with the diameter of $50 \mathrm{~mm}$ and the height of $100 \mathrm{~mm}$, made of cement mortar with the same proportion, were produced to execute the uniaxial compression tests. And the mean value of the uniaxial compressive strengths was considered as the calculated uniaxial compressive strength $(\mathrm{UCS}=21.86 \mathrm{MPa})$. The direct shear tests of unbolted joints with different normal stresses were carried out to obtain the cohesion $c_{j}$ and the basic internal friction angle $\varphi_{b}$ of samples. The shear stress-shear displacement curves of unbolted joints were presented in Figure 2.

The shear strengths of unbolted joints under different normal stress conditions were fitted by the Mohr-Coulomb strength criterion [26-28], from which the cohesion of $0.306 \mathrm{MPa}$ and the internal friction angle of $45.23^{\circ}$ can be back-calculated out. Nevertheless, for bolted joint, the bolt has not yielded when the sample reaches the peak strength, and only small deformation emerges. Therefore, it is believed that it is more reasonable to adopt the basic internal friction angle $\left(\varphi_{b}=33.94^{\circ}\right)$ corresponding to the residual strength, instead of the internal friction angle corresponding to the peak strength, to calculate the shear strength of bolted joints. The mechanical parameters related to the sample and the bolt were shown in Table 1.

2.2. Test Results. A total of 30 bolted joint samples were prepared in the tests, divided into 6 groups, that is, onebolted joints (inclination of $45^{\circ}$ and $90^{\circ}$ ), two-bolted joint (inclination of $45^{\circ}$ and $90^{\circ}$ ), three-bolted joint (inclination of $45^{\circ}$ and $90^{\circ}$ ). Each group was subjected to direct shear tests under five different normal stresses, the shear stress-shear displacement curves were obtained as shown in Figure 3, and the corresponding shear strength was shown in Table 2.

\section{Shear Strength Model of Bolted Joint}

3.1. Bolt Stress and Deformation. Generally, attributed to the dilatancy effect, both the shear displacement and the normal displacement will emerge for the bolted joints under the action of shear load [28-30]. One common assumption was made that $U_{0}$ represented the shear displacement of the joint, $U_{d}$ was the normal displacement due to shear dilatancy, and $N_{0}$ was the axial force of bolt, while $Q_{0}$ was the shear force of bolt, as shown in Figure 4 . When shearing, both axial force and shear force will be observed in the bolt under the compressive action of surrounding rock blocks, which subsequently produce axial deformation and shear deformation, ultimately resulting in approximate $S$-shaped deformation near the joint (see Figure 4). In the figure, $u_{0}$ is the axial displacement component of the bolt, $v_{0}$ is the tangential displacement component of the bolt, $P_{u}$ represents the ultimate reaction force of bolt subjected to surrounding rock material per unit length, and $\alpha$ is the inclination of the bolt. Point $O$ is the intersection between the joint and the bolt where the bending moment is zero and only axial and shear forces act in the bolt. The maximum curvature can be observed at both point $A$ and point $B$, with the maximum bending moment and no shear force.

Comprehensive analysis was conducted based on Figure 4. According to the geometric relation, it is easy to deduce the following relationship between the displacement of the bolt and joint $[19,22,31]$ :

$$
\begin{aligned}
& u_{0}=0.5\left(U_{0} \cos \alpha+U_{d} \sin \alpha\right), \\
& v_{0}=0.5\left(U_{0} \sin \alpha-U_{d} \cos \alpha\right),
\end{aligned}
$$

where $u_{0}$ is the axial displacement of point $O ; v_{0}$ is the tangential displacement of point $O ; U_{d}=U_{0} \tan \psi$; and $\psi$ is the shear dilatancy angle of the joint.

Considering the bolt as a semi-infinite beam, Hamermesh [32] detailed the deformation of the bolt and illustrated that the following relationship (equations (3) and (4)) exists between the axial displacement $u(x)$, 


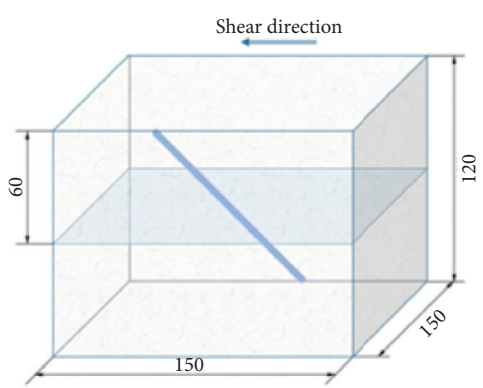

(a)

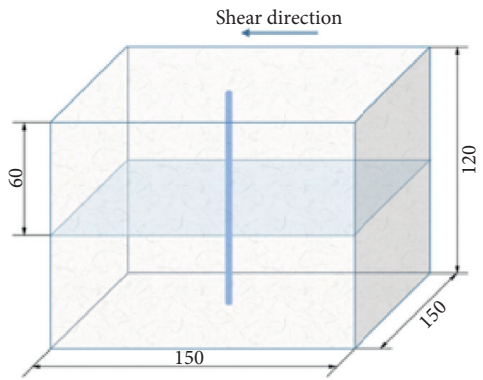

(d)

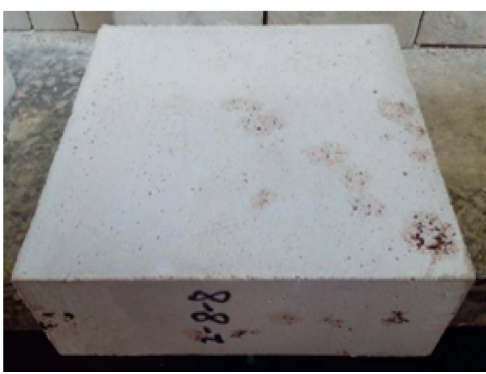

$(\mathrm{g})$

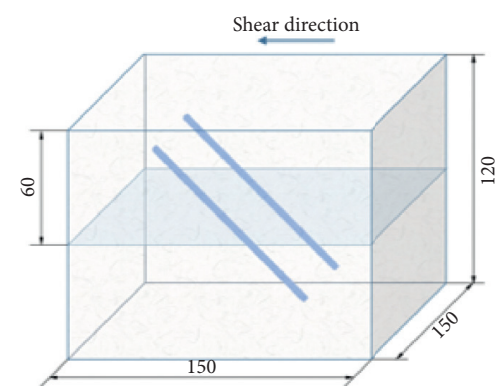

(b)

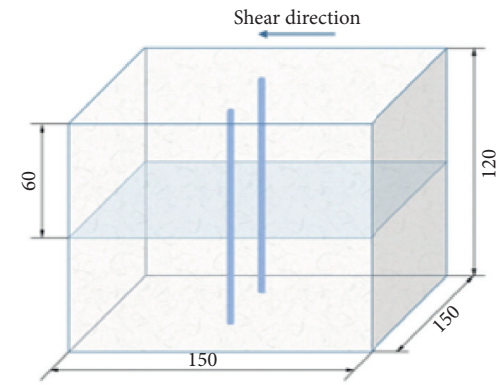

(e)

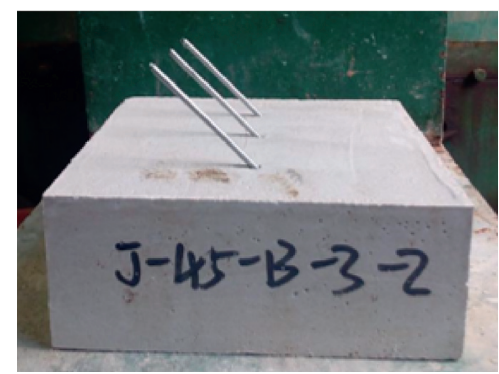

(h)

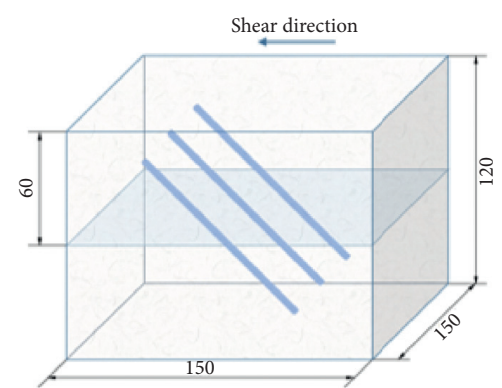

(c)

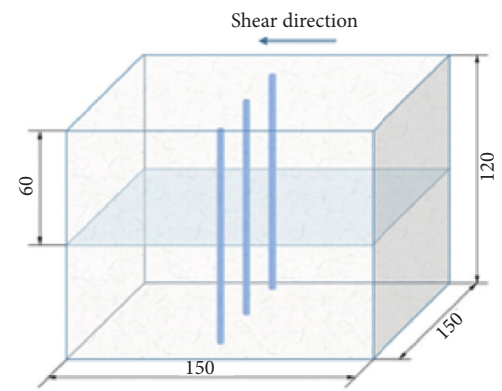

(f)

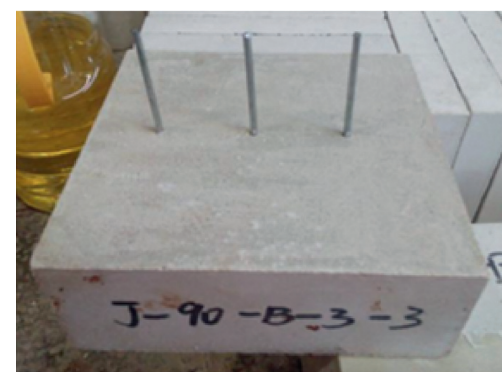

(i)

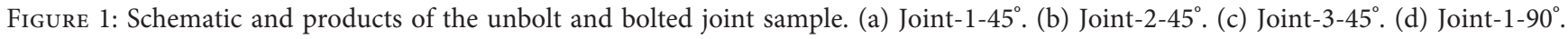
(e) Joint-2-90\%. (f) Joint $-3-90^{\circ}$. (g) Unbolted joint. (h) $45^{\circ}$ bolted joint. (i) $90^{\circ}$ bolted joint.

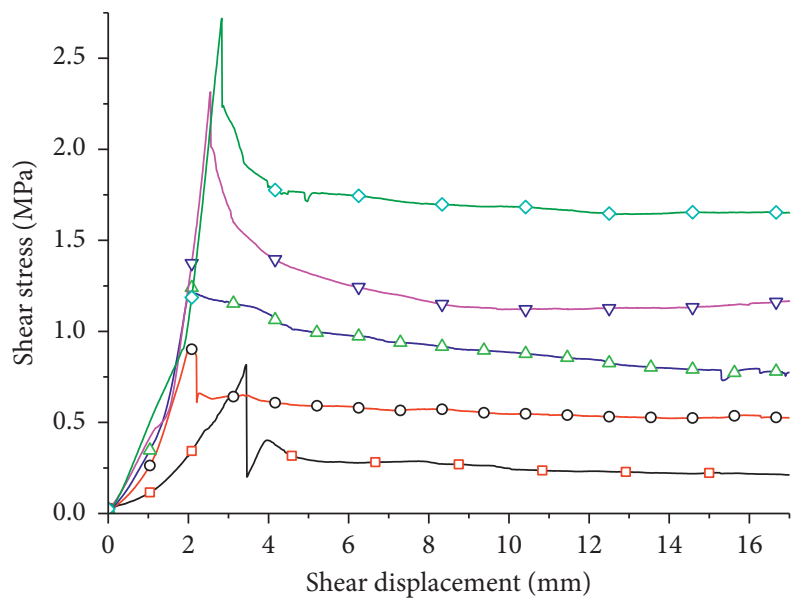

Normal stress

$$
\begin{array}{ll}
\multimap-0.45 \mathrm{MPa} & \rightarrow-1.78 \mathrm{MPa} \\
\multimap-0.89 \mathrm{MPa} & -\checkmark 2.22 \mathrm{MPa} \\
\neg-1.33 \mathrm{MPa} &
\end{array}
$$

Figure 2: Shear stress-shear displacement curve of unbolted joint. tangential displacement $v(x)$ inside the bolt, and $u_{0}$ and $v_{0}$ when shearing:

$$
\begin{aligned}
& u(x)=-u_{0}\left(1-\frac{2 x}{3 \pi l_{0}}\right), \\
& v(x)=v_{0} e^{-x / l_{0}} \cos \left(\frac{x}{l_{0}}\right),
\end{aligned}
$$

where $l_{0}=(\pi / 4) \cdot l_{A}, l_{A}$, distance between point $O$ and point A.

Based on the theory of elastic foundation beam, Pellet and Egger [33] established the elastic foundation beam model of the bolt under shear load and systematically studied the relationship between internal force and deformation during bolt shearing. The expression of the total complementary energy was obtained from the calculation of the internal strain energy and the work of the external forces. When the total complementary energy is minimized with respect to the displacements, $u_{0}$ and $v_{0}$, the relations between forces and displacements are expressed as 
TABLE 1: Mechanical parameters of sample and bolts.

\begin{tabular}{lcccc}
\hline $\begin{array}{l}\text { Elastic modulus of bolt } \\
(\mathrm{GPa})\end{array}$ & $\begin{array}{c}\text { Yield stress of bolt } \\
(\mathrm{MPa})\end{array}$ & $\begin{array}{c}\text { Uniaxial compressive strength of joint } \\
(\mathrm{MPa})\end{array}$ & $\begin{array}{c}\text { Cohesion of joint } \\
(\mathrm{MPa})\end{array}$ & $\begin{array}{c}\text { Basic friction angle of } \\
\text { joint }\left({ }^{\circ}\right)\end{array}$ \\
\hline 206 & 245 & 21.86 & 0.306 & 33.94 \\
\hline
\end{tabular}

$$
\begin{aligned}
& u_{0}=\frac{24 N_{0} Q_{0}}{E p_{u} \pi D_{b}^{2}}, \\
& v_{0}=\frac{8192 Q_{0}^{4} b}{E \pi^{4} p_{u}^{3} D_{b}^{4}},
\end{aligned}
$$

where $E$ is the elastic modulus of the bolt material, $P_{u}$ is the ultimate reacting force per unit length generated by the rock mass around the bolt, $D_{b}$ is bolt diameter, and $b=0.27$.

Under the shear load, the shear displacement of the bolted joint increases continuously. When the bolt is bent, the ultimate reaction force $P_{u}$ has a great influence on the shear strength of the joint. Holmberg [34] analyzed the influence factors of $P_{u}$ in detail, concluding that $P_{u}$ was mainly affected by the compressive strength of surrounding rock and the diameter of the bolt. And the following empirical formula was proposed:

$$
P_{u}=n \sigma_{c} D_{b}
$$

where $\sigma_{c}$ is the compressive strength of the wall rocks and $n$ is the reaction coefficient, generally ranging between 1 and 15 , which is negatively related to $\sigma_{c}$. As $\sigma_{c}$ increases, the value of $n$ decreases gradually, with a decreasing rate, which is shown in Figure 5.

3.2. Yield State of the Bolt. When the bolted joint is subjected to shear load and the shear displacement $U_{0}$ increases to a certain extent, there will be two yielding modes of the bolt: tensile shear yielding and bending yielding. When the bolt yields by tensile shear force, it obeys Von-Mises criterion and there exists a relationship between the yield stress $\sigma_{y}$ and the axial force as well as the tangential force in the bolt section, which can be expressed as follows:

$$
\sigma_{y}=\sqrt{\left(\frac{N_{0 y}}{A_{b}}\right)^{2}+3\left(\frac{Q_{0 y}}{A_{b}}\right)^{2}}
$$

where $N_{0 y}$ and $Q_{0 y}$ are the axial force and shear force acting at point $O$ at the yield stress of the bolt material, respectively, and $A_{b}$ is sectional area of bolt.

When bending to yield, the bolt yield point $A$ (or $B$ ) is subject to the combined action of axial force and bending moment. According to the beam theory of elastic foundation, the internal force of the bolt meets the following yield conditions:

$$
1.7 \sigma_{y}=\frac{M_{A}}{W}+\frac{N_{0 y}}{A_{b}},
$$

where $M_{A}=Q_{0 y}^{2} / 2 P_{u}, W=\pi D_{b}^{3} / 32$, MA is the bending moment at point $A$ (or $B$ ) of the plastic hinge, and $W$ is the static moment at the interface of the bolt.
3.3. Relationship between Normal Stress and Dilatancy Angle. During joint shearing, the dilatancy effect will emerge, due to the roughness of the joint. And the dilatancy angle $\psi$ is generally used to indicate the magnitude of the dilatancy effect. Jing [35] used a parabolic equation to describe the relationship between peak dilatancy angle and normal stress (equation (10)):

$$
\psi_{p}=\psi_{p 0}\left(1-\frac{\sigma_{n}}{\sigma_{c}}\right)^{k}
$$

where $\Psi_{p 0}$ is the initial dilatancy angle, $\sigma_{n}$ is the normal stress, and $k$ is the empirical parameter, depending on the material and the roughness of the joint, which was suggested to range from 0.2 to 5.0 .

Additionally, Schneider [36] proposed a negative exponential formula to describe the relationship between peak dilatancy and normal stress (equation (11)):

$$
\psi_{p}=\psi_{p 0} e^{-k \sigma_{n}}
$$

where $\Psi_{p o}, \sigma_{n}$, and $k$ share the same meaning as equation (10), while $k$ ranges from 0.29 to 1.89 .

Through comparison, Tang et al. [37] found that the result of equation (10) showed great consistency with that of equation (10). Therefore, both equations (10) and (11) were adopted to calculate the dilatancy angle in this paper, for guaranteeing the calculation accuracy of the dilatancy angle.

3.4. Analytical Solution for Shear Strength. Among the existing shear strength models of bolted joint, the ratio of the axial force and the shear force to the bolt sectional area $A_{b}$ is often taken as the reference to the averaging stress effect when considering the contribution of bolt to joint shear strength, while this approach that the stress in the bolt section area is simply added to the joint strength formula will lead to a large deviation to actual bolt strength contribution due to the size difference between the bolt section and the joint. Exactly, the influencing area of bolt may far exceed the total area of bolt section. Based on such an assumption, Liu et al. [17] proposed the concept of "equivalent shear area" and considered the influencing area of bolt rectangular. The equivalent shear area is defined as the product of bolt diameter $\left(D_{b}\right)$ and joint width (rock block length) or bolt interval $(L)$ :

$$
A_{e}=D_{b} \cdot L
$$

While the circular or elliptical shearing failure area of bolted joint generally emerges in practical tests, instead of rectangular, a more reasonable calculating model of shear strength of bolted joint by adopting circle as the influencing area of bolt was established in this paper (see equation (13)). 

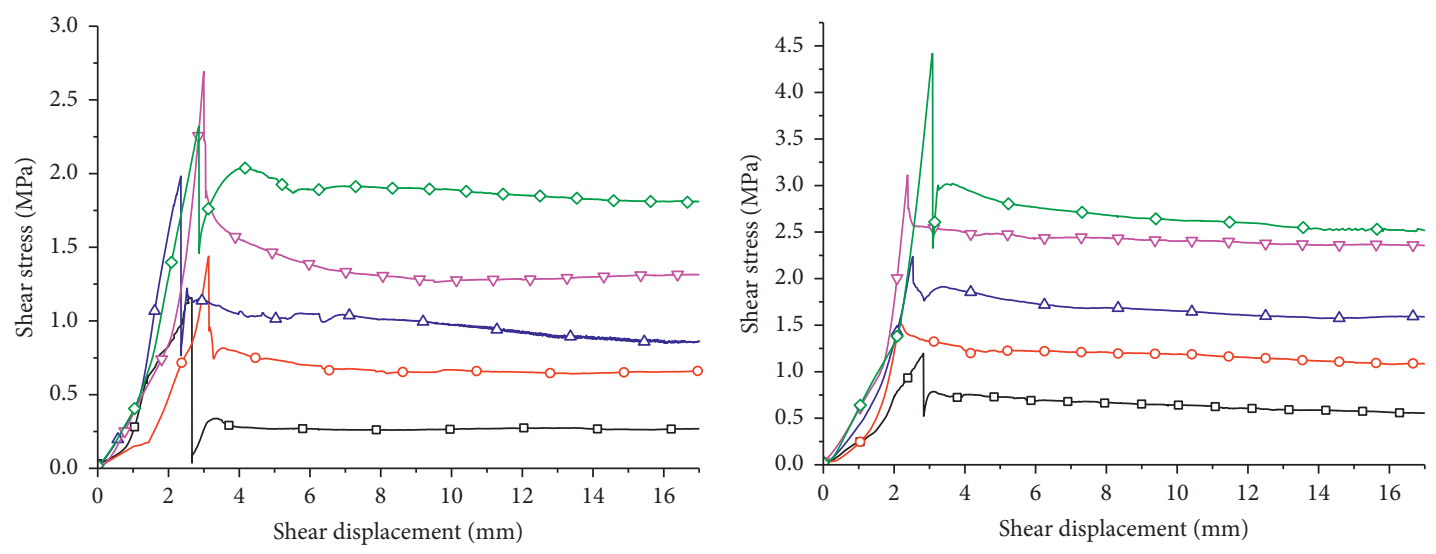

Normal stress

$\longrightarrow 0.45 \mathrm{MPa}$

$\rightarrow-1.78 \mathrm{MPa}$

$\multimap 0.89 \mathrm{MPa}$

$\diamond 2.22 \mathrm{MPa}$

(a)

Normal stress

$\rightarrow 0.45 \mathrm{MPa}$

$\rightarrow-1.78 \mathrm{MPa}$

- $0.89 \mathrm{MP}$

$\diamond 2.22 \mathrm{MPa}$

$\triangle 1.33 \mathrm{MPa}$

(b)
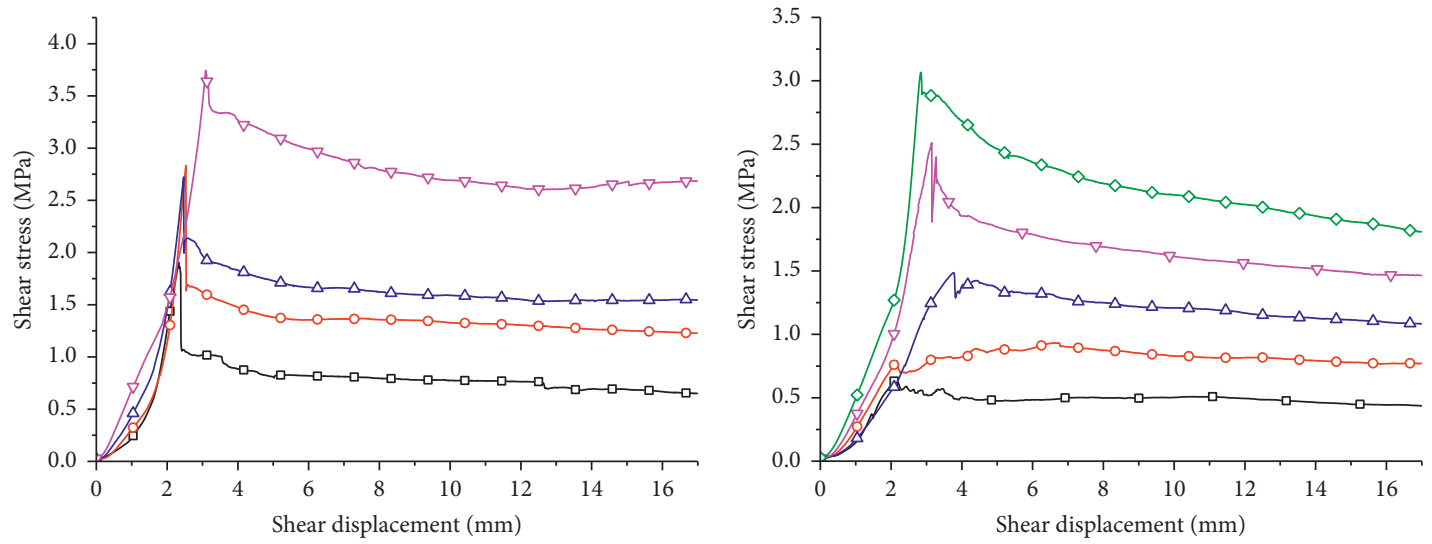

Normal stress

$\rightarrow 0-0.45 \mathrm{MPa}$

$\triangle 1.33 \mathrm{MPa}$

$-0.89 \mathrm{MPa}$

$\rightarrow \quad 2.22 \mathrm{MPa}$

(c)

Normal stress

$\rightarrow 0.45 \mathrm{MPa}$

$\multimap 0.89 \mathrm{MPa}$

$\triangle 1.33 \mathrm{MPa}$

(d)
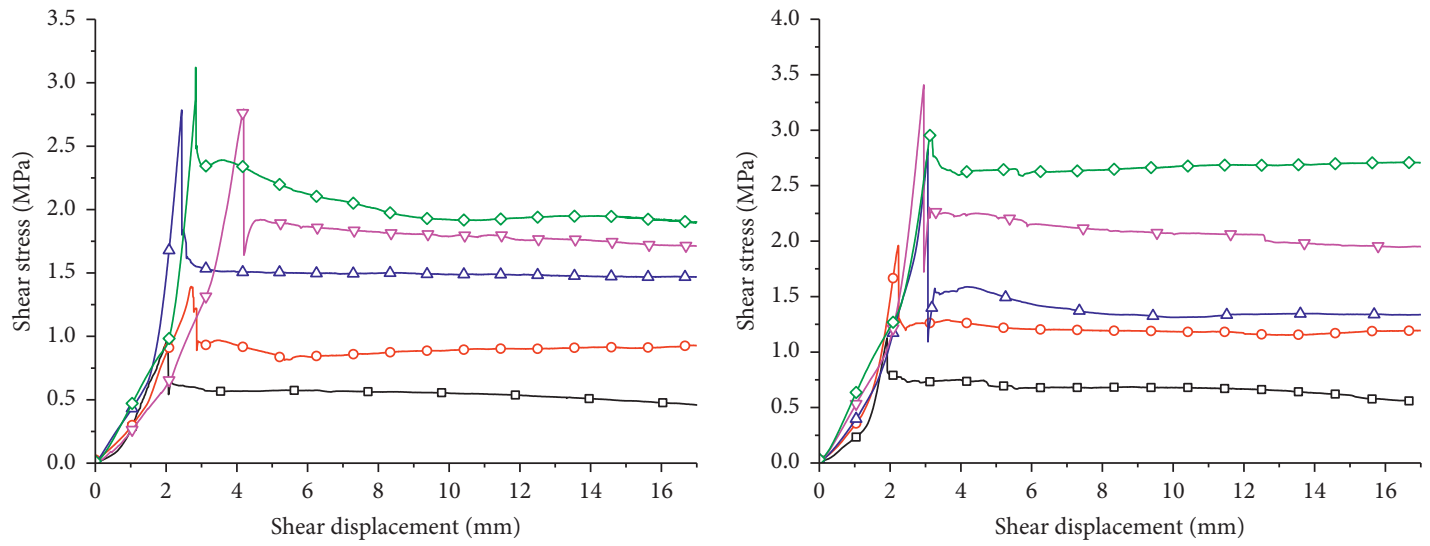

Normal stress

$\rightarrow 0.45 \mathrm{MPa}$

$\rightarrow-1.78 \mathrm{MPa}$

$\multimap 2.22 \mathrm{MPa}$

(e)

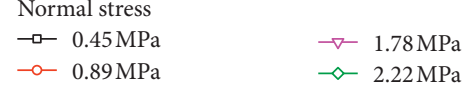

(f)

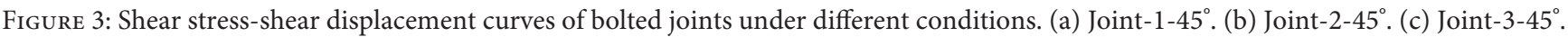

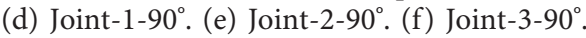


TABLE 2: Shear strength of joints under different conditions.

\begin{tabular}{|c|c|c|c|c|c|c|}
\hline \multirow{2}{*}{ Normal stress $(\mathrm{MPa})$} & \multicolumn{6}{|c|}{ Shear strength $(\mathrm{MPa})$} \\
\hline & Joint- $1-45^{\circ}$ & Joint-2- $45^{\circ}$ & Joint-3-45 & Joint-1-90 & Joint-2-90 & Joint-3-90 \\
\hline 0.45 & 1.16 & 1.20 & 1.91 & 0.65 & 0.99 & 1.13 \\
\hline 0.89 & 1.44 & 1.58 & 2.83 & 0.93 & 1.39 & 1.96 \\
\hline 1.33 & 1.98 & 2.24 & 2.72 & 1.49 & 2.79 & 2.83 \\
\hline 1.78 & 2.69 & 3.11 & 3.30 & 2.51 & 2.79 & 3.41 \\
\hline 2.22 & 2.32 & 4.42 & 3.74 & 3.07 & 3.12 & 2.98 \\
\hline
\end{tabular}

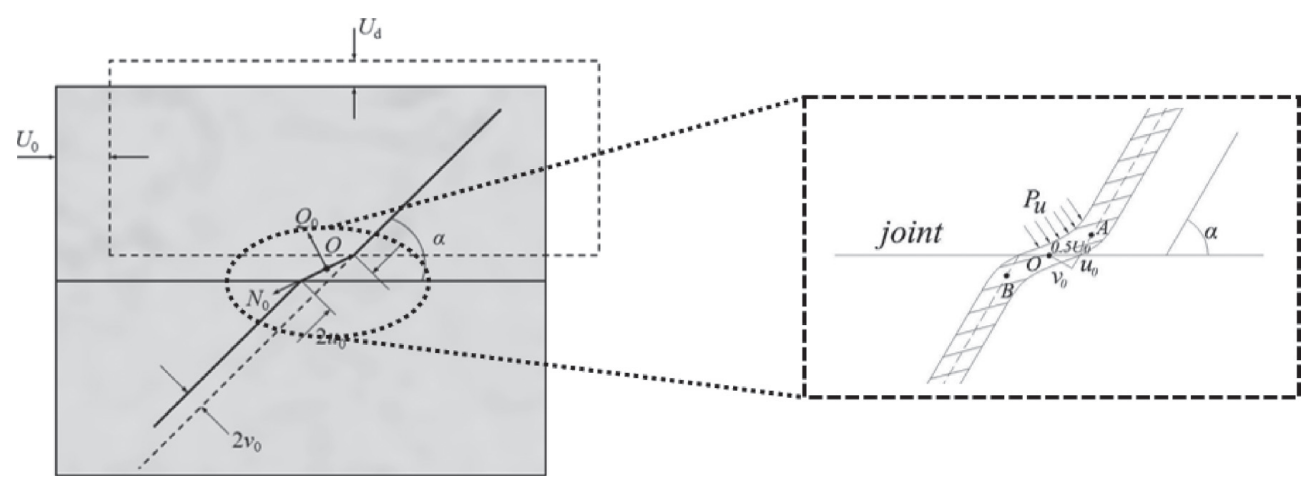

Figure 4: Schematic of joint and bolt deformation [17].

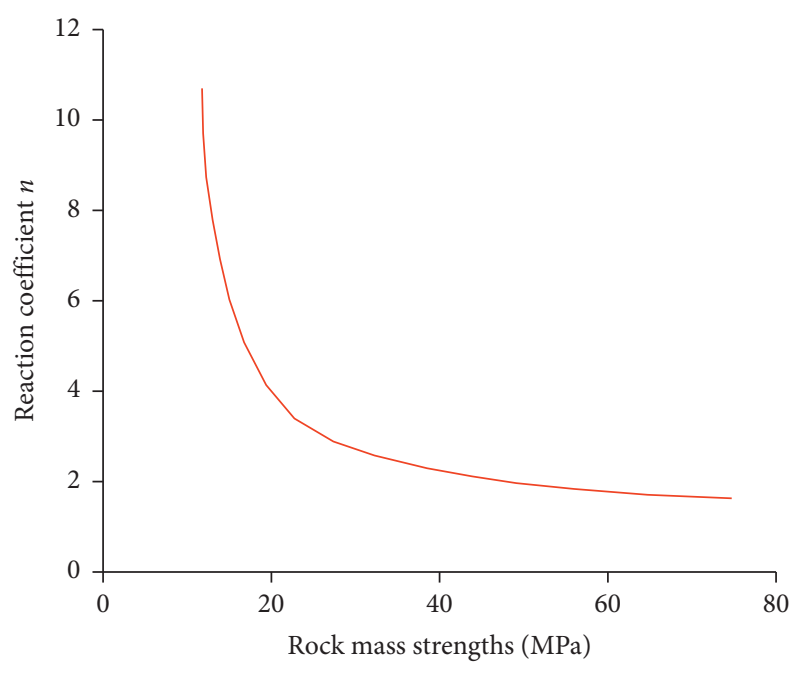

FIGURE 5: $n$ values corresponding to different rock mass strengths [34].

The bolt influence coefficient $(m)$ was introduced, which was defined as the diameter ratio of the equivalent shear area to the bolt (see Figure 6). With the increase of bolt number, their intervals become smaller and the group bolting effect (the coincidence of the influencing area of bolt) should be taken into consideration. In this case, the reduction to the bolt strength is unavoidable, and the reduction factor is beyond the scope of this study, remaining to be further studied in the subsequent researches and investigations.

$$
A_{e}=\frac{\pi}{4}\left(m \cdot D_{b}\right)^{2} \cdot a,
$$

where $a$ is the number of the bolt.

According to the mechanical analysis of bolt, the shear strength of the bolted joint can be divided into three parts: (1) the joint shear strength; (2) the shear strength provided by the tangential force of bolt; (3) the shear strength provided by the axial force of bolt. Thus, the expression of the bolted joint shear strength $\tau$ can be termed as

$$
\tau=\tau_{j}+\tau_{b a}+\tau_{b t},
$$

where $\tau_{j}=\sigma_{j} \tan \left(\phi_{b}+\psi\right)+c_{j}, \quad \tau_{b a}=\left(N_{0 y} / A_{e}\right)[\sin \alpha \tan$ $\left.\left(\phi_{b}+\psi\right)+\cos \alpha\right], \tau_{b t}=\left(Q_{0 y} / A_{e}\right)\left[\sin \alpha-\cos \alpha \tan \left(\phi_{b}+\psi\right)\right]$, $\tau_{j}$ is the shear strength of joint, $\sigma_{j}$ is the normal stress of joint, $\tau_{b a}$ is the shear strength provided by the tangential force of bolt, $\tau_{b t}$ is the shear strength provided by the axial force of bolt, $\alpha$ is the inclination angle of bolt, and $A_{e}$ is the equivalent shear area of bolt.

In this study, EXCEL programming was used to calculate the shear strength of bolted joints. Based on an initial shear displacement $U_{0}$, according to equations (1), (2), (5), and (6), the bolt axial force $N_{0}$ and the shear force $Q_{0}$ could be, respectively, obtained, which were adopted to measure whether equations (8) or (9) were satisfied. If not, iteratively calculation of the above steps was conducted until the satisfaction of equations (8) or (9). Then, it was possible to obtain the relevant computational parameters of $U_{0}, U_{d}, N_{0 y}$, $Q_{0 y}, u_{0}$, and $v_{0}$ of bolt when it yields by tension or bending. The bolt shear displacement when yielding determines the yielding mode. Finally, when the bolt was subjected to tensile shear yielding or bending yielding, the axial force $N_{0 y}$ and the shear force $Q_{0 y}$ were substituted into equation (14), and the shear strength of bolted joint under any normal stress could be obtained. 


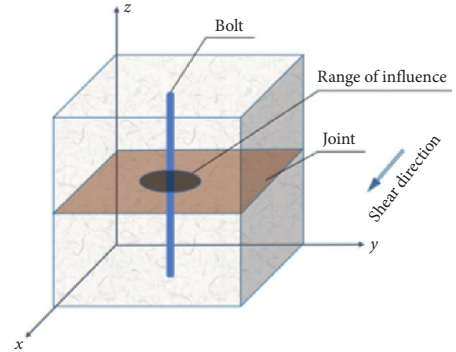

(a)

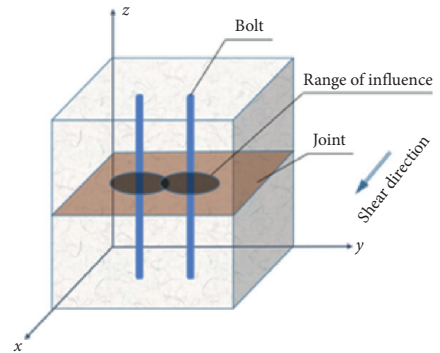

(b)

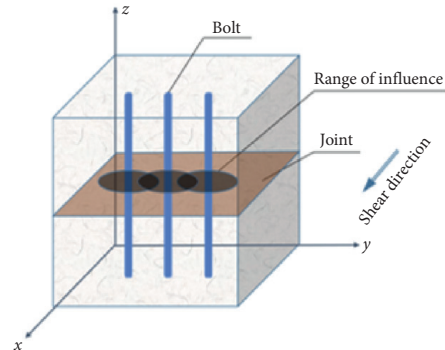

(c)

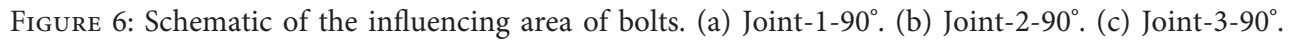

TABLE 3: Comparison of test results with theoretical calculation results.

\begin{tabular}{|c|c|c|c|c|c|c|c|c|c|c|c|c|c|c|c|}
\hline \multirow{3}{*}{ Normal stress $(\mathrm{MPa})$} & \multicolumn{15}{|c|}{ Shear strength $(\mathrm{MPa})$} \\
\hline & \multirow{2}{*}{$\tau_{\text {test }}$} & \multicolumn{2}{|c|}{$m=10$} & \multicolumn{2}{|c|}{$m=20$} & \multicolumn{2}{|c|}{$m=30$} & \multicolumn{2}{|c|}{$m=40$} & \multicolumn{2}{|c|}{$m=50^{\#}$} & \multicolumn{2}{|c|}{$m=52$} & \multicolumn{2}{|c|}{$m=56.42^{*}$} \\
\hline & & $\tau_{\mathrm{cal}}$ & $E(\%)$ & $\tau_{\mathrm{cal}}$ & $E(\%)$ & $\tau_{\mathrm{cal}}$ & $E(\%)$ & $\tau_{\mathrm{cal}}$ & $E(\%)$ & $\tau_{\text {cal }}$ & $E(\%)$ & $\tau_{\mathrm{cal}}$ & $E(\%)$ & $\tau_{\text {cal }}$ & $E(\%)$ \\
\hline \multicolumn{16}{|l|}{ (a) Joint-1-45 } \\
\hline 0.45 & 1.16 & 4.06 & 250.0 & 1.66 & 43.1 & 1.22 & 5.2 & 1.06 & 8.6 & 0.99 & 14.7 & 0.98 & 15.5 & 0.96 & 17.2 \\
\hline 0.89 & 1.44 & 4.60 & 219.4 & 2.20 & 52.8 & 1.76 & 22.2 & 1.60 & 11.1 & 1.53 & 6.3 & 1.52 & 5.6 & 1.50 & 4.2 \\
\hline 1.33 & 1.98 & 5.14 & 159.6 & 2.74 & 38.4 & 2.30 & 16.2 & 2.14 & 8.1 & 2.07 & 4.5 & 2.06 & 4.0 & 2.05 & 3.5 \\
\hline 1.78 & 2.69 & 5.70 & 111.9 & 3.30 & 22.7 & 2.85 & 6.0 & 2.70 & 0.4 & 2.63 & 2.2 & 2.62 & 2.6 & 2.60 & 3.3 \\
\hline 2.22 & 2.32 & 6.24 & 169.0 & 3.84 & 65.5 & 3.40 & 46.6 & 3.24 & 40.0 & 3.17 & 36.6 & 3.16 & 36.2 & 3.14 & 35.3 \\
\hline$E_{\text {ave }}(\%)$ & & & 182.0 & & 44.5 & & 19.2 & & 13.6 & & 12.9 & & 12.8 & & 12.7 \\
\hline \multicolumn{16}{|l|}{ (b) Joint-2-45 } \\
\hline 0.45 & 1.20 & 4.44 & 270.0 & 1.82 & 51.7 & 1.51 & 25.8 & 1.34 & 11.7 & 1.26 & 5.0 & 1.23 & 2.5 & 1.17 & 2.5 \\
\hline 0.89 & 1.58 & 5.07 & 220.9 & 2.45 & 55.1 & 2.13 & 34.8 & 1.96 & 24.1 & 1.89 & 19.6 & 1.86 & 17.7 & 1.79 & 13.3 \\
\hline 1.33 & 2.24 & 5.69 & 154.0 & 3.07 & 37.1 & 2.76 & 23.2 & 2.59 & 15.6 & 2.52 & 12.5 & 2.49 & 11.2 & 2.42 & 8.0 \\
\hline 1.78 & 3.11 & 6.33 & 103.5 & 3.72 & 19.6 & 3.40 & 9.3 & 3.23 & 3.9 & 3.16 & 1.6 & 3.13 & 0.6 & 3.06 & 1.6 \\
\hline 2.22 & 4.42 & 6.96 & 57.5 & 4.34 & 1.8 & 4.03 & 8.8 & 3.86 & 12.7 & 3.78 & 14.5 & 3.75 & 15.2 & 3.69 & 16.5 \\
\hline$E_{\text {ave }}(\%)$ & & & 161.2 & & 33.1 & & 20.4 & & 13.6 & & 10.6 & & 9.4 & & 8.4 \\
\hline \multicolumn{16}{|l|}{ (c) Joint-3-45 } \\
\hline 0.45 & 1.91 & 4.64 & 142.9 & 2.62 & 37.2 & 1.91 & 0 & 1.58 & 17.3 & 1.46 & 23.6 & 1.40 & 26.7 & 1.34 & 29.8 \\
\hline 0.89 & 2.83 & 5.32 & 88.0 & 3.29 & 16.3 & 2.59 & 8.5 & 2.26 & 20.1 & 2.14 & 24.4 & 2.08 & 26.5 & 2.02 & 28.6 \\
\hline 1.33 & 2.72 & 6.00 & 120.6 & 3.97 & 46.0 & 3.26 & 19.9 & 2.93 & 7.7 & 2.81 & 3.3 & 2.75 & 1.1 & 2.69 & 1.1 \\
\hline 1.78 & 3.30 & 6.69 & 102.7 & 4.66 & 41.2 & 3.95 & 19.7 & 3.62 & 9.7 & 3.51 & 6.4 & 3.45 & 4.5 & 3.38 & 2.4 \\
\hline 2.22 & 3.74 & 7.36 & 96.8 & 5.34 & 42.8 & 4.63 & 23.8 & 4.30 & 15.0 & 4.18 & 11.8 & 4.12 & 10.2 & 4.06 & 8.6 \\
\hline$E_{\text {ave }}(\%)$ & & & 110.2 & & 36.7 & & 14.4 & & 14.0 & & 13.9 & & 13.8 & & 14.1 \\
\hline \multicolumn{16}{|l|}{ (d) Joint-1-90 } \\
\hline 0.45 & 0.65 & 2.35 & 261.5 & 1.18 & 81.5 & 0.96 & 47.7 & 0.89 & 36.9 & 0.85 & 30.8 & 0.85 & 30.8 & 0.84 & 29.2 \\
\hline 0.89 & 0.93 & 2.82 & 203.2 & 1.65 & 77.4 & 1.43 & 53.8 & 1.36 & 46.2 & 1.32 & 41.9 & 1.32 & 41.9 & 1.31 & 40.9 \\
\hline 1.33 & 1.49 & 3.29 & 120.8 & 2.12 & 42.3 & 1.90 & 27.5 & 1.83 & 22.8 & 1.79 & 20.1 & 1.79 & 20.1 & 1.78 & 19.5 \\
\hline 1.78 & 2.51 & 3.77 & 50.2 & 2.60 & 3.6 & 2.38 & 5.2 & 2.31 & 8.0 & 2.27 & 9.6 & 2.27 & 9.6 & 2.26 & 10.0 \\
\hline 2.22 & 3.07 & 4.24 & 38.1 & 3.07 & 0 & 2.86 & 6.8 & 2.78 & 9.4 & 2.74 & 10.7 & 2.74 & 10.7 & 2.73 & 11.1 \\
\hline$E_{\mathrm{ave}}(\%)$ & & & 134.8 & & 41.0 & & 28.2 & & 24.7 & & 22.6 & & 22.6 & & 22.1 \\
\hline \multicolumn{16}{|l|}{ (e) Joint-2-90 } \\
\hline 0.45 & 0.99 & 2.68 & 170.7 & 1.31 & 32.3 & 1.15 & 16.2 & 1.06 & 7.1 & 1.02 & 3.0 & 1.01 & 2.0 & 0.98 & 1.0 \\
\hline 0.89 & 1.39 & 3.22 & 131.7 & 1.86 & 33.8 & 1.69 & 21.6 & 1.60 & 15.1 & 1.57 & 12.9 & 1.55 & 11.5 & 1.52 & 9.4 \\
\hline 1.33 & 2.79 & 3.76 & 34.8 & 2.40 & 14.0 & 2.24 & 19.7 & 2.15 & 22.9 & 2.11 & 24.4 & 2.09 & 25.1 & 2.06 & 26.2 \\
\hline 1.78 & 2.79 & 4.32 & 54.8 & 2.95 & 5.7 & 2.79 & 0 & 2.70 & 3.2 & 2.66 & 4.7 & 2.65 & 5.0 & 2.61 & 6.5 \\
\hline 2.22 & 3.12 & 4.86 & 55.8 & 3.50 & 12.2 & 3.33 & 6.7 & 3.24 & 3.8 & 3.21 & 2.9 & 3.19 & 2.2 & 3.16 & 1.3 \\
\hline$E_{\text {ave }}(\%)$ & & & 89.6 & & 19.6 & & 12.8 & & 10.4 & & 9.6 & & 9.2 & & 8.9 \\
\hline \multicolumn{16}{|l|}{ (f) Joint-3-90 } \\
\hline 0.45 & 1.13 & 3.44 & 204.4 & 2.10 & 85.8 & 1.63 & 44.2 & 1.41 & 24.8 & 1.33 & 17.7 & 1.29 & 14.2 & 1.25 & 10.6 \\
\hline 0.89 & 1.96 & 4.14 & 111.2 & 2.80 & 42.9 & 2.33 & 18.9 & 2.11 & 7.7 & 2.04 & 4.1 & 2.00 & 2.0 & 1.95 & 0.5 \\
\hline 1.33 & 2.83 & 4.85 & 71.4 & 3.50 & 23.7 & 3.03 & 7.1 & 2.82 & 0.4 & 2.74 & 3.2 & 2.70 & 4.6 & 2.66 & 6.0 \\
\hline 1.78 & 3.41 & 5.57 & 63.3 & 4.22 & 23.8 & 3.75 & 10.0 & 3.53 & 3.5 & 3.46 & 1.5 & 3.42 & 0.3 & 3.38 & 0.9 \\
\hline 2.22 & 2.98 & 6.27 & 110.4 & 4.93 & 65.4 & 4.45 & 49.3 & 4.24 & 42.3 & 4.16 & 39.6 & 4.12 & 38.3 & 4.08 & 36.9 \\
\hline$E_{\text {ave }}(\%)$ & & & 112.1 & & 48.3 & & 25.9 & & 15.7 & & 13.2 & & 11.9 & & 11.0 \\
\hline
\end{tabular}

Note: $m$ with “*” indicates the equivalent shear area covering the whole joint; $m$ with “\#” indicates the equivalent shear area covering the inscribed circle area of joint. 


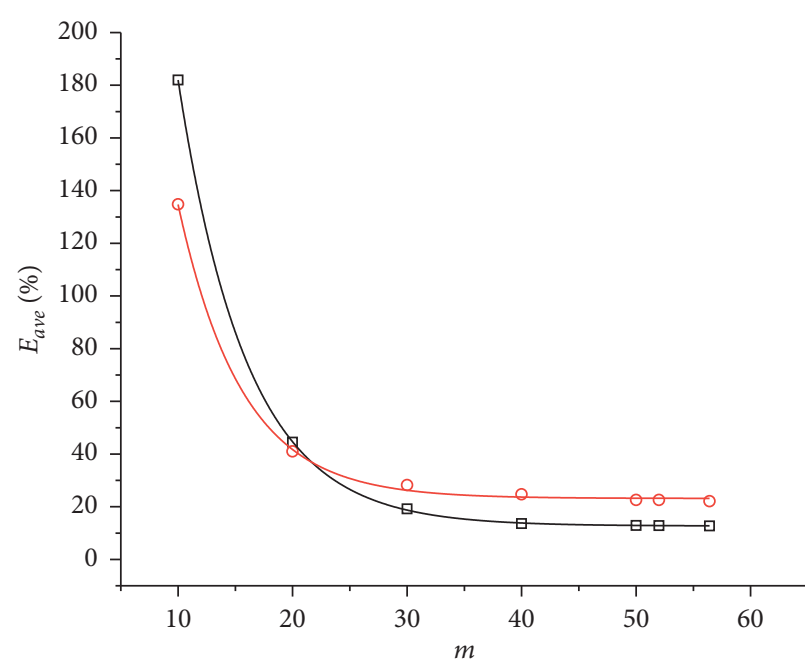

Joint $-1-45^{\circ}$

- Joint $-1-90^{\circ}$

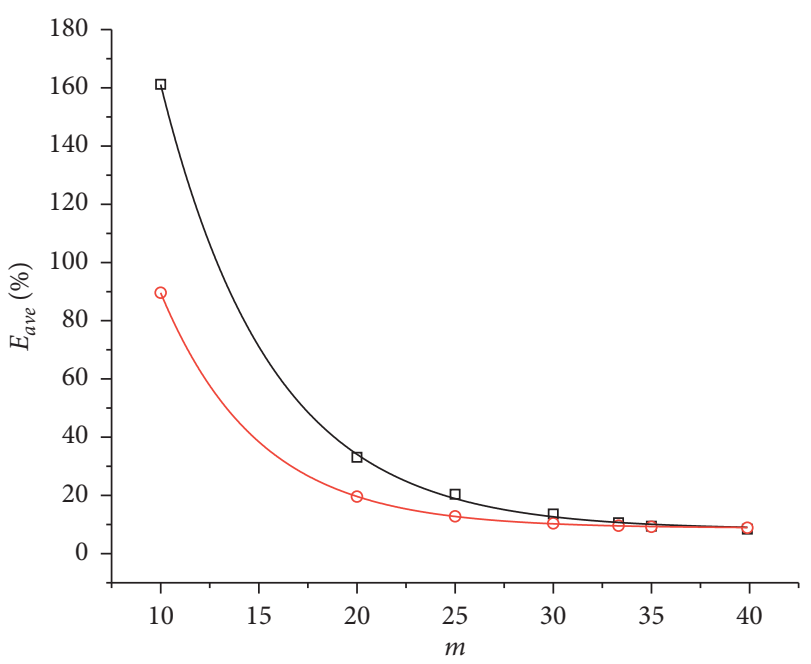

口 Joint $-2-45^{\circ}$

ㄱ Joint $-2-90^{\circ}$

(a)

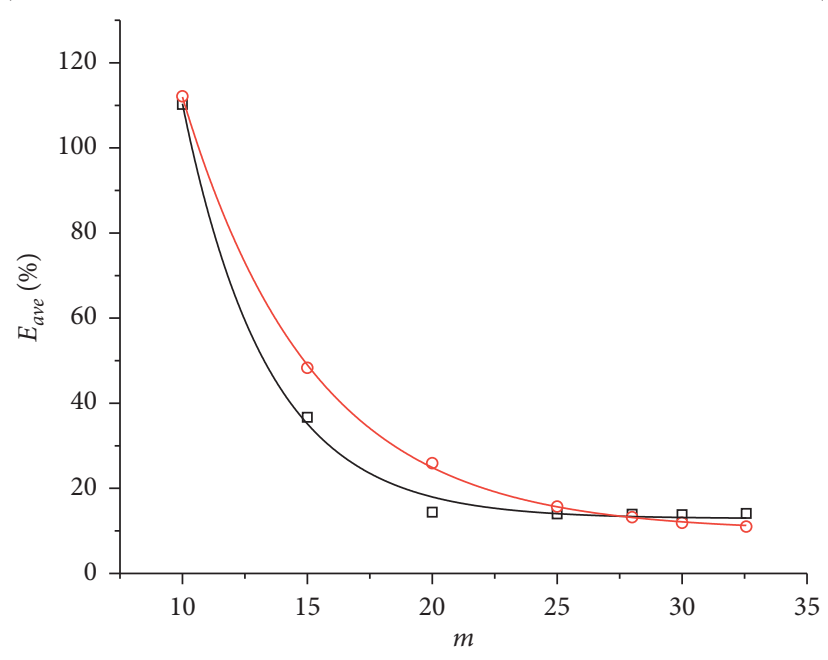

口 Joint $-3-45^{\circ}$

- Joint $-3-90^{\circ}$

(c)

FiguRE 7: Relationship between $E_{\text {ave }}$ and $m$. (a) Joint with one bolt. (b) Joint with two bolts. (c) Joint with three bolts.

\section{Verification}

As described in Figure 5, when the compressive strength is $21.86 \mathrm{MPa}$, the ultimate reaction coefficient $n$ is 3.5 . According to the calculation procedure of the bolted joint shear strength proposed in Section 3.4, through changing the value of the bolt influence coefficient $m$ and using the EXCEL programming, the shear strength of the bolted joint under any normal stress could be obtained. Compared to the test results in Section 2.2, the relative error and its average value were selected to evaluate the accuracy of the calculation (see Table 3, wherein $\tau_{\text {test }}$ is the test result, $\tau_{\text {cal }}$ is the calculated result, $E$ is the relative error, and $E_{\text {ave }}$ is the average relative error).

The average relative error [21] is calculated as

$$
E_{\text {ave }}=\frac{1}{n} \sum_{i=1}^{n}\left|\frac{\tau_{\text {test }}-\tau_{\text {cal }}}{\tau_{\text {test }}}\right| \times 100 \%
$$

The comprehensive comparison of theoretical results and test results was carried out according to Table 3, which illustrates that the smallest difference between calculating values and test results, corresponding to the relative error of $0.5 \%$, emerges for Joint $-3-90^{\circ}$ under the normal stress of $0.89 \mathrm{MPa}(m=32.57)$, while the greatest difference, with the relative error of $40.9 \%$, was observed for Joint $-1-90^{\circ}$ under the normal stress of $0.89 \mathrm{MPa}(m=56.42)$. Besides, the maximum of average relative error is $22.1 \%$ and the minimum is $8.4 \%$. Except for the individual abnormal test values, the relative errors are all basically less than $20 \%$, indicating 


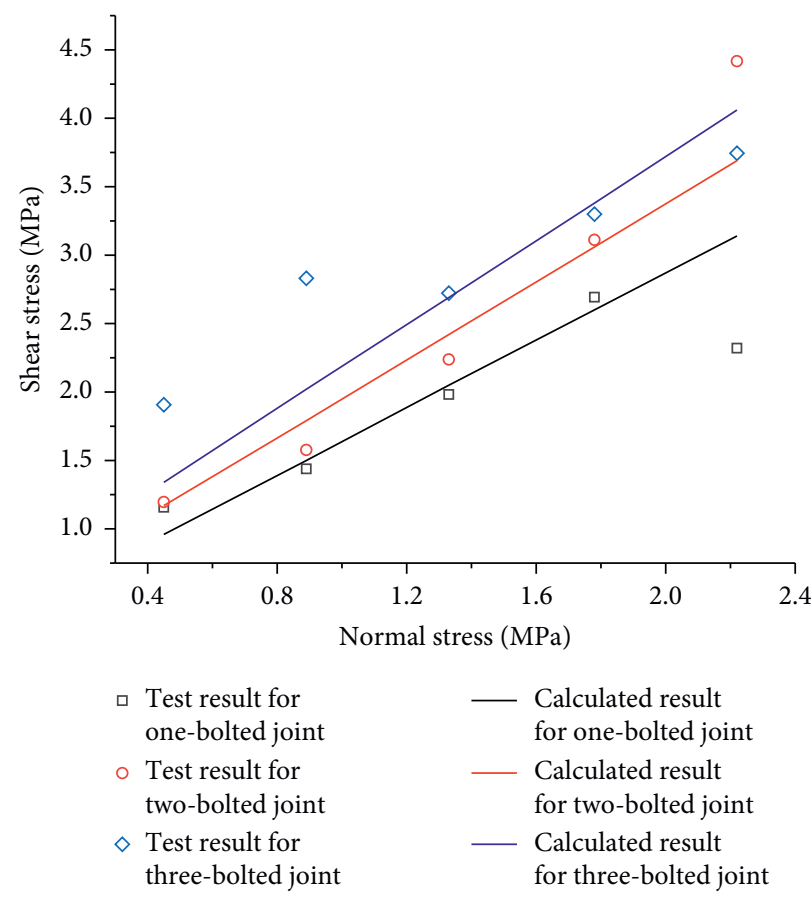

(a)

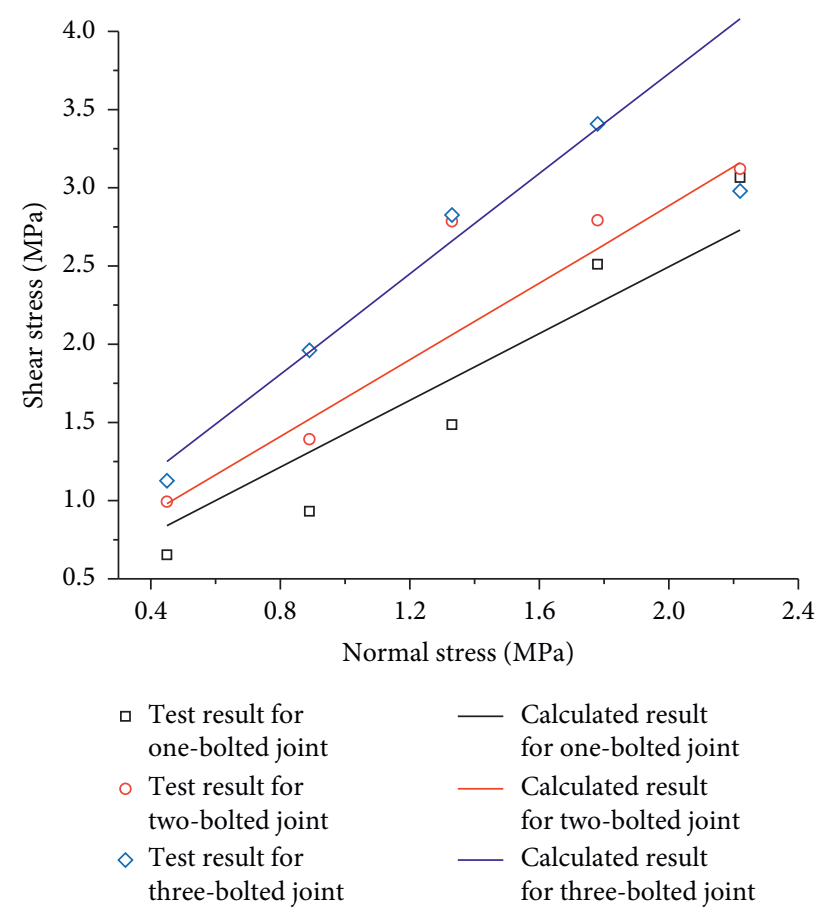

(b)

FIGURE 8: Comparison of test results with optimal calculated values. (a) $45^{\circ}$ inclination. (b) $90^{\circ}$ inclination.

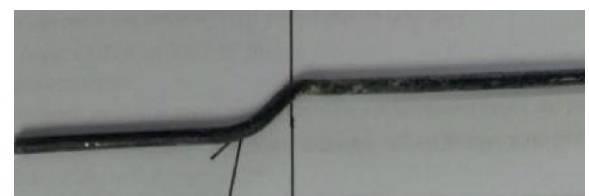

(a)

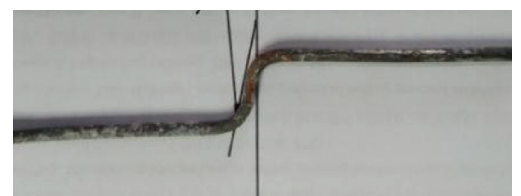

(b)

FIgURE 9: Shear deformation of the bolt with different inclinations. (a) $45^{\circ}$ inclination. (b) $90^{\circ}$ inclination.

that the theoretical results are in great agreement with the test results. Therefore, the value of the bolt influence coefficient $m$ with the smallest average relative error was selected to calculate the equivalent shear area. If the average relative errors are equal, then the influence coefficient $m$ with the smallest variance was taken.

As nonlinear curves fitting results shown in Figure 7, there exists a negative correlation between the value of $E_{\text {ave }}$ and $m$. And it can be observed that $E_{\text {ave }}$ tends to stabilize with slight fluctuations of the curve when $m$ is greater than 30 (see Figure $7(\mathrm{a}))$ ). For two-bolted joints, $E_{\text {ave }}$ stays steady when $m$ is greater than 25 (see Figure 7(b))), while for threebolted joint, the theoretical model agrees well with the test results when $m$ is greater than 20 (see Figure $7(\mathrm{c}))$ ). The comparison between the optimal calculated results (the underlined $E_{\text {ave }}$ values in Table 3 ) and the test results in this study is shown in Figure 8. It can be concluded that the theoretical results are generally greater than the test results, which can be attributed to the idealization of the stress state of bolts during the calculation, as well as the ignorance of the group bolting effect.
After the direct shear tests were completed, the bolts were removed and the bolt deformations are shown in Figure 9. It is found that the connection between the bolt and the sample is intact, while an obvious crushing area between the bolt and the joint can be observed. The bolts were nearly $\mathrm{S}$-shaped, and the shear deformation length is about 3 to 5 times the bolt diameter, which indicates that the tangential deformation of the bolt is dominant during the joint shearing process. According to the test observation, the bolt basically showed bending failure, which is consistent with the theoretical calculation results in Section 3.4. In the case where the bolt was $45^{\circ}$ obliquely intersected with the joint, both the axial drawing effect and the tangential antishearing effect were exerted, producing small tangential shear deformation of the bolt. And when $90^{\circ}$ bolting was used to reinforce the joint, the bolt mainly contributed to pin effect during shearing, leading to great tangential shear deformation.

To verify the validity of the circular influencing area of bolt, a comprehensive comparison of calculating results was made with the rectangular influencing area. According to the 
TABLE 4: Comparison between calculated and measured values of shear strength of the two models.

\begin{tabular}{|c|c|c|c|c|c|c|}
\hline \multirow{2}{*}{ Category } & \multirow{2}{*}{ Normal stress $(\mathrm{MPa})$} & \multirow{2}{*}{$\tau_{\text {test }}(\mathrm{MPa})$} & \multicolumn{2}{|c|}{ Rectangle } & \multicolumn{2}{|c|}{ Circle } \\
\hline & & & $\tau_{\mathrm{cal}}(\mathrm{MPa})$ & $E(\%)$ & $\tau_{\mathrm{cal}}(\mathrm{MPa})$ & $E(\%)$ \\
\hline \multirow{5}{*}{ Joint- $1-45^{\circ}$} & 0.45 & 1.16 & 5.89 & 407.8 & 0.96 & 17.2 \\
\hline & 0.89 & 1.44 & 6.43 & 346.5 & 1.50 & 4.2 \\
\hline & 1.33 & 1.98 & 6.97 & 252.0 & 2.05 & 3.5 \\
\hline & 1.78 & 2.69 & 7.52 & 179.6 & 2.60 & 3.3 \\
\hline & 2.22 & 2.32 & 8.07 & 247.8 & 3.14 & 35.3 \\
\hline \multirow{5}{*}{ Joint-2-45 } & 0.45 & 1.20 & 6.43 & 435.8 & 1.17 & 2.5 \\
\hline & 0.89 & 1.58 & 7.06 & 346.8 & 1.79 & 13.3 \\
\hline & 1.33 & 2.24 & 7.68 & 242.9 & 2.42 & 8.0 \\
\hline & 1.78 & 3.11 & 8.33 & 167.8 & 3.06 & 1.6 \\
\hline & 2.22 & 4.42 & 8.95 & 102.5 & 3.69 & 16.5 \\
\hline \multirow{5}{*}{ Joint- $3-45^{\circ}$} & 0.45 & 1.91 & 6.73 & 252.4 & 1.40 & 26.7 \\
\hline & 0.89 & 2.83 & 7.40 & 161.5 & 2.08 & 26.5 \\
\hline & 1.33 & 2.72 & 8.08 & 197.1 & 2.75 & 1.1 \\
\hline & 1.78 & 3.30 & 8.77 & 165.8 & 3.45 & 4.5 \\
\hline & 2.22 & 3.74 & 9.45 & 152.7 & 4.12 & 10.2 \\
\hline \multirow{5}{*}{ Joint-1-90 } & 0.45 & 0.65 & 3.24 & 398.5 & 0.84 & 29.2 \\
\hline & 0.89 & 0.93 & 3.71 & 298.9 & 1.31 & 40.9 \\
\hline & 1.33 & 1.49 & 4.18 & 180.5 & 1.78 & 19.5 \\
\hline & 1.78 & 2.51 & 4.67 & 86.1 & 2.26 & 10.0 \\
\hline & 2.22 & 3.07 & 5.14 & 67.4 & 2.73 & 11.1 \\
\hline \multirow{5}{*}{ Joint-2-90 } & 0.45 & 0.99 & 3.71 & 274.7 & 0.98 & 1.0 \\
\hline & 0.89 & 1.39 & 4.26 & 206.5 & 1.52 & 9.4 \\
\hline & 1.33 & 2.79 & 4.80 & 72.0 & 2.06 & 26.2 \\
\hline & 1.78 & 2.79 & 5.35 & 91.8 & 2.61 & 6.5 \\
\hline & 2.22 & 3.12 & 5.89 & 88.8 & 3.16 & 1.3 \\
\hline \multirow{5}{*}{ Joint-3-90 } & 0.45 & 1.13 & 4.82 & 326.5 & 1.25 & 10.6 \\
\hline & 0.89 & 1.96 & 5.52 & 181.6 & 1.95 & 0.5 \\
\hline & 1.33 & 2.83 & 6.23 & 120.1 & 2.66 & 6.0 \\
\hline & 1.78 & 3.41 & 6.95 & 103.8 & 3.38 & 0.9 \\
\hline & 2.22 & 2.98 & 7.65 & 156.7 & 4.08 & 36.9 \\
\hline$E_{\text {ave }}(\%)$ & & & & 210.5 & & 12.8 \\
\hline
\end{tabular}

experimental results of shear strengths in Section 2.2, the calculating results of shear strengths considering circular influencing area and rectangular influencing area were obtained, respectively. And the differences between the test results and calculating results for both influencing areas were solved according to equation (15), which are shown in Table 4. Obviously, considerable deviations can be observed from the values of $E$ for the rectangular influencing area, up to $210.5 \%$, while the values of $E$ for the other approximate only to $12.8 \%$, which makes it evident that the calculating model of shear strength considering the circular influencing area of the bolt is superior, with smaller $E$ and accurate calculating results.

\section{Conclusion}

(1) Considering the actual shear failure mode of bolted joint, based on the assumption of the circular influencing area of bolt, a theoretical calculation model for the shear strength of bolted joint was proposed.

(2) Changing the number and the inclination of bolt, the results obtained by direct shear tests on bolted joint present great consistency with the calculating results, which verified the validity of the proposed model.
(3) The influence coefficient $m$ significantly affects the shear strength of bolted joint. And when $m$ reaches a certain value, the theoretical relative error between the calculating results and test results tends to be stable and sufficiently small. In such case, the area, corresponding to $m$, can be considered as the actual influencing area of the bolt.

\section{Data Availability}

Some or all data, models, or codes generated or used during the study are available from the corresponding author upon request.

\section{Conflicts of Interest}

The authors declare no conflicts of interest.

\section{Acknowledgments}

This paper got its funding from Project 51774322 supported by National Natural Science Foundation of China; Project 2018JJ2500 supported by Hunan Provincial Natural Science Foundation of China; Project 2020JGB135 supported by Degree \& Postgraduate Education Reform Project of Central 
South University. The authors wish to acknowledge these supports.

\section{References}

[1] Y. Chen, P. Cao, D. Mao, C. Pu, and X. Fan, "Morphological analysis of sheared rock with water-rock interaction effect," International Journal of Rock Mechanics and Mining Sciences, vol. 70, pp. 264-272, 2014.

[2] C. Zhang, P. Zou, Y. Wang, T. Jiang, H. Lin, and P. Cao, “An elasto-visco-plastic model based on stress functions for deformation and damage of water-saturated rocks during the freeze-thaw process," Construction and Building Materials, vol. 250, Article ID 118862, 2020.

[3] Y. Zhao, Y. Wang, W. Wang, L. Tang, Q. Liu, and G. Cheng, "Modeling of rheological fracture behavior of rock cracks subjected to hydraulic pressure and far field stresses," Theoretical and Applied Fracture Mechanics, vol. 101, pp. 59-66, 2019.

[4] Y. Wang, H. Zhang, H. Lin, Y. Zhao, X. Li, and Y. Liu, "Mechanical behavior and failure analysis of fracture-filled gneissic granite," Theoretical and Applied Fracture Mechanics, vol. 108, Article ID 102674, 2020.

[5] Y. Zhao, L. Zhang, W. Wang, C. Pu, W. Wan, and J. Tang, "Cracking and stress-strain behavior of rock-like material containing two flaws under uniaxial compression," Rock Mechanics and Rock Engineering, vol. 49, no. 7, pp. 26652687, 2016.

[6] R. Yong, J. Ye, B. Li, and S.-G. Du, "Determining the maximum sampling interval in rock joint roughness measurements using fourier series," International Journal of Rock Mechanics and Mining Sciences, vol. 101, pp. 78-88, 2018.

[7] W. Yuan, J. Li, Z. Li, W. Wang, and X. Sun, "A strength reduction method based on the generalized hoek-brown (GHB) criterion for rock slope stability analysis," Computers and Geotechnics, vol. 117, Article ID 103240, 2020.

[8] R.-h. Cao, C. Wang, R. Yao et al., "Effects of cyclic freeze-thaw treatments on the fracture characteristics of sandstone under different fracture modes: laboratory testing," Theoretical and Applied Fracture Mechanics, vol. 109, Article ID 102738, 2020.

[9] R. Cao, R. Yao, J. Meng, Q. Lin, H. Lin, and S. Li, "Failure mechanism of non-persistent jointed rock-like specimens under uniaxial loading: laboratory testing," International Journal of Rock Mechanics and Mining Sciences, vol. 132, Article ID 104341, 2020.

[10] N. Chen, X. Zhang, Q. Jiang, X. Feng, W. Wei, and B. Yi, "Shear behavior of rough rock joints reinforced by bolts," International Journal of Geomechanics, vol. 18, Article ID 4017130, 2018.

[11] Y. Chen, "Experimental study and stress analysis of rock bolt anchorage performance," Journal of Rock Mechanics and Geotechnical Engineering, vol. 6, no. 5, pp. 428-437, 2014.

[12] B. Meng, H. Jing, S. Yang, T. Cui, and B. Li, "Experimental study on shear behavior of bolted cement mortar blocks under constant normal stiffness," KSCE Journal of Civil Engineering, vol. 23, no. 8, pp. 3724-3734, 2019.

[13] S. Maghous, D. Bernaud, and E. Couto, "Three-dimensional numerical simulation of rock deformation in bolt-supported tunnels: a homogenization approach," Tunnelling and Underground Space Technology, vol. 31, pp. 68-79, 2012.

[14] G. Grasselli, "3D behaviour of bolted rock joints: experimental and numerical study," International Journal of Rock Mechanics and Mining Sciences, vol. 42, no. 1, pp. 13-24, 2005.
[15] H. Lin, Y. Zhu, J. Yang, and Z. Wen, "Anchor stress and deformation of the bolted joint under shearing," Advances in Civil Engineering, vol. 2020, Article ID 3696489, 10 pages, 2020.

[16] W. Q. Chen, Z. X. Jia, Y. F. Zhao, L. P. Liu, J. J. Zhou, and X. C. Lin, "Analysis of axial and transverse effects of rock bolt during shearing process," Rock \& Soil Mechanics, vol. 36, pp. 143-148, 2015.

[17] Q. S. Liu, G. F. Lei, X. X. Peng, and L. Wei, "Shearing mechanical model and experimental verification of bolts in jointed rock mass," Chinese Journal of Geotechnical Engineering, vol. 40, pp. 794-801, 2018.

[18] J. Y. Teng, Y. N. Zhang, J. X. Zhang, and C. Zhang, "Experimental study on shear behavior of jointed rock mass with anchorage mode," Rock and Soil Mechanics, vol. 38, pp. 2279-2285, 2017.

[19] H. Lin, P. Sun, Y. Chen, Y. Zhu, X. Fan, and Y. Zhao, "Analytical and experimental analysis of the shear strength of bolted saw-tooth joints," European Journal of Environmental and Civil Engineering, vol. 24, pp. 1-15, 2020.

[20] J. Shen, Z. Shu, M. Cai, and S. Du, "A shear strength model for anisotropic blocky rock masses with persistent joints," International Journal of Rock Mechanics and Mining Sciences, vol. 134, Article ID 104430, 2020.

[21] W.-c. Fan, P. Cao, and L. Long, "Degradation of joint surface morphology, shear behavior and closure characteristics during cyclic loading," Journal of Central South University, vol. 25, no. 3, pp. 653-661, 2018.

[22] H. Lin, P. Sun, Y. Chen, Y. Wang, and Y. Zhao, "Shear behavior of bolt-reinforced joint rock under varying stress environment," Geotechnical and Geological Engineering, vol. 38, no. 6, pp. 5755-5770, 2020.

[23] Q. Lin, P. Cao, J. Meng, R. Cao, and Z. Zhao, "Strength and failure characteristics of jointed rock mass with double circular holes under uniaxial compression: insights from discrete element method modelling," Theoretical and Applied Fracture Mechanics, vol. 109, Article ID 102692, 2020.

[24] Q. Lin, P. Cao, R. Cao, H. Lin, and J. Meng, "Mechanical behavior around double circular openings in a jointed rock mass under uniaxial compression," Archives of Civil and Mechanical Engineering, vol. 20, no. 1, p. 19, 2020.

[25] X. Fan, P. H. S. W. Kulatilake, X. Chen, and P. Cao, "Crack initiation stress and strain of jointed rock containing multicracks under uniaxial compressive loading: a particle flow code approach," Journal of Central South University, vol. 22, no. 2, pp. 638-645, 2015.

[26] Y. Zhao, L. Zhang, J. Liao, W. Wang, Q. Liu, and L. Tang, "Experimental study of fracture toughness and subcritical crack growth of three rocks under different environments," International Journal of Geomechanics, vol. 20, Article ID 4020128, 2020.

[27] K. Li, Y. Cheng, Z. Y. Yin, D. Han, and J. Meng, "Size effects in a transversely isotropic rock under brazilian tests: laboratory testing," Rock Mechanics and Rock Engineering, vol. 53, no. 6, pp. 2623-2642, 2020.

[28] D. Han, K. Li, and J. Meng, "Evolution of nonlinear elasticity and crack damage of rock joint under cyclic tension," International Journal of Rock Mechanics and Mining Sciences, vol. 128, Article ID 104286, 2020.

[29] W. Yang, G. Li, P. Ranjith, and L. Fang, "An experimental study of mechanical behavior of brittle rock-like specimens with multi-non-persistent joints under uniaxial compression and damage analysis," International Journal of Damage Mechanics, vol. 28, no. 10, pp. 1490-1522, 2019. 
[30] P. Štefane, S. Naib, S. Hertelé, W. De Waele, and N. Gubeljak, "Crack tip constraint analysis in welded joints with pronounced strength and toughness heterogeneity," Theoretical and Applied Fracture Mechanics, vol. 103, Article ID 102293, 2019.

[31] X. Ge and J. Liu, "Study on the shear resistance behaviour of bolted rock joints," Chinese Jounal of Geotechnical Engineering, vol. 10, pp. 8-19, 1988.

[32] M. Hamermesh, Beams on Elastic Foundation: Theory with Applications in the Fields of Civil and Mechanical Engineering, University of Michigan, Ann Arbor, MI, USA, 1958.

[33] F. Pellet and P. Egger, "Analytical model for the mechanical behaviour of bolted rock joints subjected to shearing," Rock Mechanics and Rock Engineering, vol. 29, no. 2, pp. 73-97, 1996.

[34] M. Holmberg, The Mechanical Behavior of Untensioned Grouted Rock Bolts, Royal Institute of Technology, Stockholm, Sweden, 1991.

[35] L. Jing, Numerical Modeling of Jointed Rock Masses by Distinct Element Method for Two and Three-Dimensional Problems, Lulea University of Technology, Luleå, Sweden, 1990.

[36] H. J. Schneider, "The friction and deformation behaviour of rock joints," Rock Mechanics Felsmechanik Mecanique des Roches, vol. 8, no. 3, pp. 169-184, 1976.

[37] Z. C. Tang, C. C. Xia, and Y. L. Song, "Analysis of peak dilation strength and model of peak dilation angle for artificial joint," Chinese Journal of Rock Mechanics \& Engineering, vol. 31, pp. 3038-3044, 2012. 